\title{
A Randomized Clinical Trial of the Effect of Continuous Glucose Monitoring on Nocturnal Hypoglycemia, Daytime Hypoglycemia, Glycemic Variability, and Hypoglycemia Confidence in Persons with Type 1 Diabetes Treated with Multiple Daily Insulin Injections (GOLD-3)
}

\author{
Arndís F. Ólafsdóttir, RN, PgD, ${ }^{1,2}$ William Polonsky, PhD, Jan Bolinder, MD, PhD, FRCPE, \\ Irl B. Hirsch, MD, Sofia Dahlqvist, ${ }^{5}$ Hans Wedel, $\mathrm{PhD}^{6}$ Thomas Nyström, MD, PhD, \\ Magnus Wijkman, MD, PhD, Erik Schwarcz, MD, PhD, Jarl Hellman, MD, ${ }^{10}$ \\ Tim Heise, MD, ${ }^{11}$ and Marcus Lind, MD, PhD,
}

\begin{abstract}
Background: To evaluate the effects of continuous glucose monitoring (CGM) on nocturnal and daytime hypoglycemia in persons with type 1 diabetes treated with multiple daily insulin injections (MDI); we also evaluated factors related to differences in hypoglycemia confidence in this population.

Methods: Evaluations were performed from the GOLD randomized trial, an open-label multicenter crossover randomized clinical trial $(n=161)$ over 69 weeks comparing CGM to self-measurement of blood glucose (SMBG) in persons with type 1 diabetes treated with MDI. Masked CGM and the hypoglycemia confidence questionnaire were used for evaluations.

Results: Time with nocturnal hypoglycemia, glucose levels $<70 \mathrm{mg} / \mathrm{dL}$ was reduced by $48 \%$ (10.2 vs. $19.6 \mathrm{~min}$ each night, $P<0.001$ ) and glucose levels $<54 \mathrm{mg} / \mathrm{dL}$ by $65 \%$. ( 3.1 vs. $8.9 \mathrm{~min}, P<0.001$ ). For the corresponding glucose cutoffs, daytime hypoglycemia was reduced by $40 \%$ ( 29 vs. $49 \mathrm{~min}, P<0.001$ ) and $54 \%$ (8 vs. $18 \mathrm{~min}$., $P<0.001)$, respectively. Compared with SMBG, CGM use improved hypoglycemia-related confidence in social situations $(P=0.016)$ and confidence in more broadly avoiding serious problems due to hypoglycemia $(P=0.0020)$. Persons also reported greater confidence in detecting and responding to decreasing blood glucose levels (thereby avoiding hypoglycemia) during CGM use $(P=0.0033)$ and indicated greater conviction that they could more freely live their lives despite the risk of hypoglycemia $(P=0.022)$.
\end{abstract}

\footnotetext{
${ }^{1}$ Department of Medicine, NU - Hospital Group, Trollhättan/Uddevalla, Sweden.

${ }^{2}$ Department of Molecular and Clinical Medicine, University of Gothenburg, Gothenburg, Sweden.

${ }^{3}$ Department of Psychiatry, University of California, San Diego, California.

${ }^{4}$ Department of Medicine, Karolinska University Hospital Huddinge, Karolinska Institutet, Stockholm, Sweden.

${ }^{5}$ School of Medicine, University of Washington, Seattle, Washington.

${ }^{6}$ Health Metrics Sahlgrenska Academy, University of Gothenburg, Gothenburg, Sweden.

${ }^{7}$ Department of Clinical Science and Education, Södersjukhuset, Karolinska Institutet, Stockholm, Sweden.

${ }^{8}$ Department of Internal Medicine and Department of Medical and Health Sciences, Linköping University, Norrköping, Sweden.

${ }^{9}$ Department of Internal Medicine, Faculty of Medicine and Health, Örebro University, Örebro, Sweden.

${ }^{10}$ Department of Medical Sciences, Clinical Diabetes and Metabolism, Uppsala University, Uppsala, Sweden.

${ }^{11}$ Profil, Neuss, Germany.
}

(C) Arndís F. Ólafsdóttir, et al., 2018; Published by Mary Ann Liebert, Inc. This Open Access article is distributed under the terms of the Creative Commons Attribution Noncommercial License (http://creativecommons.org/licenses/by-nc/4.0/) which permits any noncommercial use, distribution, and reproduction in any medium, provided the original author(s) and the source are credited. 
Conclusion: CGM reduced time in both nocturnal and daytime hypoglycemia in persons with type 1 diabetes treated with MDI and improved hypoglycemia-related confidence, especially in social situations, thus contributing to greater well-being and quality of life. Trial registration: ClinicalTrials.gov, number NCT02092051.

Keywords: Type 1 diabetes mellitus, Continuous glucose monitoring, Randomized clinical trial, Hypoglycemia, Hypoglycemia fear.

$\mathbf{C}_{\mathrm{s}}^{\mathrm{o}}$ ONVENTIONAL INTENSIVE INSULIN therapy resulting in good glycemic control has been shown to prevent and reduce the progression of diabetes-related complications in persons with type 1 diabetes. ${ }^{1,2}$ Intensive glycemic control is generally achieved through multiple daily insulin injections (MDI) or continuous subcutaneous insulin infusions (CSII) through an insulin pump. ${ }^{3}$ Regular capillary selfmeasurement of blood glucose (SMBG) values has been crucial for optimal insulin dosing and good glycemic control. ${ }^{4-6}$ While lowering mean glucose levels by this conventional intensive regime, the risk of hypoglycemia associated with impaired well-being and acute risks simultaneously increases. ${ }^{1}$ Hence, conventional intensive therapy has drawbacks when it comes to the risk of hypoglycemia.

In a recent randomized crossover trial, we showed that intensive therapy in adults with type 1 diabetes treated with MDI could be more effective in improving glycemic control by using continuous glucose monitoring (CGM). ${ }^{7}$ Among other factors, CGM also improved overall hypoglycemia confidence. Hemoglobin A1c (HbA1c) was reduced by $0.43 \%$ ( $4.7 \mathrm{mmol} / \mathrm{mol}$ ) and participants needed continual use of CGM to have a sustained effect on HbA1c. Regarding hypoglycemia, only overall estimates were presented as $40 \mathrm{~min} / 24 \mathrm{~h}$ during CGM therapy and $69 \mathrm{~min} / 24 \mathrm{~h}$ during conventional therapy. Differences regarding time in nocturnal and daytime hypoglycemia, episodes or how the effect changes when CGM therapy discontinues were not analyzed.

There were two main aims of the current study: (1) To increase understanding of CGM's effects on hypoglycemia in persons with type 1 diabetes treated with MDI, and (2) To improve the understanding of CGM's effects on hypoglycemia confidence in daily life in this population.

\section{Methods}

The GOLD study was approved by the Ethics Committee of the University of Gothenburg, Gothenburg, Sweden (December 12, 2013, diary number 857-13). All participants gave verbal and written informed consent to participate.

The study was an investigator-initiated randomized, openlabel, clinical trial with a crossover design conducted at 15 sites in Sweden. It took place from February 24, 2014 to June 1, 2016. After a run-in period of up to 6 weeks, participants were randomized to either CGM or conventional treatment for 26 weeks, with a 17-week washout period between treatment phases (Supplementary Fig. S1; Supplementary Data are available at http://online.liebertpub.com/doi/suppl/10 .1089/dia.2017.0363).

\section{Screening}

Persons 18 years or older with type 1 diabetes and HbA1c $\geq 7.5 \%(58 \mathrm{mmol} / \mathrm{mol})$ treated with $\mathrm{MDI}$ were included.
Patients were required to have a fasting C-peptide level $<0.91 \mathrm{ng} / \mathrm{mL}$ and diabetes duration $>1$ year. Patients treated with insulin pumps were excluded. The study design, including other inclusion and exclusion criteria, has been described in detail in earlier publications.

\section{Run-in period}

During a 6-week run-in phase, participants completed masked CGM for 2 weeks and questionnaires on hypoglycemic confidence (Hypoglycemia Confidence Questionnaire). ${ }^{9}$ During masked CGM, glucose levels were recorded but not seen by participants. After masked CGM, participants were excluded if they either did not believe they would wear the CGM sensor more than $80 \%$ of the time or did not perform adequate calibrations during run-in (on average at least 12 of 14 during a 7-day period).

\section{Randomization}

Participants were randomized 1:1 into the first treatment phase, stratified by site, to CGM using the Dexcom G4 PLATINUM (San Diego, CA), stand-alone system or conventional therapy.

\section{Treatment}

CGM was compared with conventional therapy using only self-monitoring of blood glucose. All participants received basic instruction on insulin dosing, such as bolus correction, food choices, and the effect of physical activity on glucose control. A graph was displayed showing the proportion of insulin at the time of injection and the proportion of insulin remaining to give effect at various time points after injection. ${ }^{10}$ The participants received guidelines for interpreting glucose levels and trends obtained by the CGM. ${ }^{8}$

During the first week, no alarms were set on the CGM device for low glucose levels, except for acute hypoglycemia $(<55 \mathrm{mg} / \mathrm{dL} ;<3.1 \mathrm{mmol} / \mathrm{L})$. Alarm settings were introduced no later than 2 weeks after randomization. At each visit, participants were encouraged to use CGM information at least every $1-2 \mathrm{~h}$ during daytime. In the conventional group, participants were encouraged to measure blood glucose levels according to guidelines (i.e., at least four times daily). Participants were instructed to adjust insulin dosages based on SMBG and not CGM values. During the 17-week washout period participants used conventional therapy and masked CGM was performed during the last 2 weeks.

\section{Clinical assessments}

Participants were assessed at the start of each treatment phase and weeks $2,4,13$, and 26. HbA1c was measured at all visits in each treatment phase, except week 2. 
Masked CGM was performed 2 weeks before both treatment phases. During conventional therapy, masked CGM was also performed during 2 of the last 4 weeks to evaluate total time in hypoglycemia, euglycemia, hyperglycemia, and glycemic variability. At all visits, CGM and SMBG data were downloaded and used for optimizing glycemic control. Participants were not allowed to have any extra visits for improving glycemic control to keep the number of visits equal in both treatment groups.

\section{Endpoints}

In this study, we evaluate time in nocturnal hypoglycemia during CGM and conventional therapy, which was a predefined endpoint in the GOLD-Study statistical analysis plan. We evaluated this for two different hypoglycemia cutoffs, $70 \mathrm{mg} / \mathrm{dL}(<3.9 \mathrm{mmol} / \mathrm{L})$ and $54 \mathrm{mg} / \mathrm{dL}(<3.0 \mathrm{mmol} / \mathrm{L})$. Furthermore, we used two different time frames for nocturnal hypoglycemia, 22:00-05:59 and 00:00-05:59, since this varied in earlier studies. ${ }^{11,12}$ The corresponding hypoglycemia cutoffs were used to evaluate daytime hypoglycemia and for both time periods 06:00-23:59 and 06:00-21:59. When analyzing time in hypoglycemia, every CGM reading below the hypoglycemia cutoffs was used. We also analyzed the number of episodes of hypoglycemia during CGM versus conventional treatment for the same glucose cutoffs and for the same time frames used to evaluate time in hypoglycemia. An episode was defined as single CGM reading below the glucose cutoff and a new episode was not counted until the sensor glucose was consistently above $70 \mathrm{mg} / \mathrm{dL}(3.9 \mathrm{mmol} / \mathrm{L})$ or above $54 \mathrm{mg} / \mathrm{dL}(3.0 \mathrm{mmol} / \mathrm{L})$ for at least 15 consecutive minutes, that is, three CGM readings. In addition, we analyzed how the effect on time in hypoglycemia for the glucose cutoffs varied over time when participants were on and off CGM therapy during various phases of the trial.

The Hypoglycemia Confidence Scale is a nine-item selfreporting questionnaire that examines the degree to which persons with diabetes feel able, secure, and comfortable about their ability to avoid hypoglycemic-related problems (Table 4). ${ }^{9}$ Items target both specific areas of concern (e.g., "how confident are you that you can stay safe from serious problems with hypoglycemia when you are exercising") and more general areas (e.g., "how confident are you that you can catch and respond to hypoglycemia before your blood sugars get too low?). Each item was rated on a four-point scale (1= "not confident at all," $2=$ "a little confident," $3=$ "moderately confident," and $4=$ "very confident") and summed to provide a total scaled score.

Time with nocturnal hypoglycemia, time with daytime hypoglycemia, and each of the 9 questions included in the hypoglycemia questionnaire were compared for the two treatment groups, CGM versus SMBG. Severe hypoglycemia was defined as unconsciousness from hypoglycemia or requiring assistance from another person.

\section{Glycemic variability}

The coefficient of variation (CV), standard deviation (SD)/ mean, was a predefined endpoint in the original statistical analysis plan. We analyzed the overall CV for CGM and conventional therapy as well as for nocturnal and daytime periods using the same time frames as for evaluations of hypoglycemia. Participants answered the questionnaire at the start and end of each treatment phase. In addition, we analyzed the mean amplitude of glycemic excursions (MAGE) ${ }^{13}$ and SD for nocturnal and daytime periods.

\section{Statistics}

Continuous variables were described by mean, SD, median, range and $95 \%$ confidence intervals (CI) where applicable, and categorical variables by number and percentage. The difference between CGM and conventional therapy for the full analysis set (FAS), that is, all participants with at least one efficacy variable recorded for treatment phases, with respect to non-normally distributed data was tested using Fisher's nonparametric two-sample permutation test, with sequence as the dependent variable and difference of the testing variable between periods, at the end of week 26 and week 69 , as the independent variable.

Sensitivity analysis using multiple imputation (MI), with SAS procedures PROC MI and PROC MIANALYZE, were performed, including demographics and baseline characteristics in a first MI analysis and also including HbA1c and time in/number of episodes of hypoglycemia in a second MI analysis. For this purpose, the main analysis were performed using generalized estimating equations with negative binomial distribution and log-link functions from which relative risks (RR) and 95\% CI were obtained. The difference between treatments with respect to glycemic variability variables was analyzed by using the procedure of generalized linear models for a crossover design.

All tests were two-tailed and conducted at a 0.05 significance level. All analyses were performed using SAS software version 9.4 (SAS Institute, Cary, NC).

\section{Results \\ Patient characteristics}

There were 161 participants randomized between February and December 2014, of whom 142 (88.0\%) had follow-up data during both treatment phases in the FAS population. Characteristics of participants in the FAS population per treatment sequence are shown in Table 1. The mean (SD) age was 44.6 (12.7) years and $53.6 \%$ were men. Mean HbA1c (SD) was $8.7(0.84) \%[72(9.1) \mathrm{mmol} / \mathrm{mol}]$ and mean diabetes duration (SD) was 22.2 (11.8) years.

\section{Time with nocturnal and daytime hypoglycemia}

The proportion of daily time with hypoglycemia $(<70 \mathrm{mg} / \mathrm{dL}$, $<3.9 \mathrm{mmol} / \mathrm{L}$ ) during CGM use, was less than during conventional therapy, $2.79 \%$ (40 min) versus $4.79 \%$ (69 min), with $P<0.001$. This was even found for glucose levels $<54 \mathrm{mg} / \mathrm{dL}$ $(<3.0 \mathrm{mmol} / \mathrm{L}), 0.79 \%$ (11 $\mathrm{min}$ ) versus $1.89 \%$ (27 min), with $P<0.001$. For participants randomized to start with CGM therapy the time in hypoglycemia decreased during CGM therapy, but increased when CGM therapy was stopped and the washout period started and reverted back to levels in accordance with conventional therapy (Fig. 1). In contrast, participants first randomized to conventional therapy reduced their time in hypoglycemia first when initiating CGM during the second treatment phase (Fig. 1).

Time spent in nocturnal hypoglycemia was less during CGM use for both the evaluated glucose levels of $<54 \mathrm{mg} / \mathrm{dL}$ and $<70 \mathrm{mg} / \mathrm{dL}(<3.0 \mathrm{mmol} / \mathrm{L}$ and $<3.9 \mathrm{mmol} / \mathrm{L})$ irrespective 
Table 1. Clinical Characteristics of the Full Analyses Set Population per Treatment Sequence

\begin{tabular}{|c|c|c|}
\hline Variable & $\begin{array}{c}\text { CGM }(\text { DexCom G4)/ } \\
\text { conventional } \\
\text { therapy }(\mathrm{n}=69)\end{array}$ & $\begin{array}{c}\text { Conventional } \\
\text { therapy/CGM } \\
\text { (DexCom G4) }(\mathrm{n}=73)\end{array}$ \\
\hline Age & $46.7(43.6-49.8)$ & $42.6(39.8-45.5)$ \\
\hline \multicolumn{3}{|c|}{ 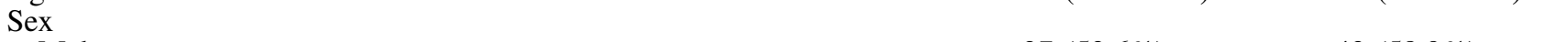 } \\
\hline Male & $37(53.6 \%)$ & $43(58.9 \%)$ \\
\hline Female & $32(46.4 \%)$ & $30(41.1 \%)$ \\
\hline Weight $(\mathrm{kg})$ at randomization visit & $81.3(77.7-84.8)$ & $83.0(79.0-87.0)$ \\
\hline BMI $\left(\mathrm{kg} / \mathrm{m}^{2}\right)$ at randomization visit & $27.0(26.1-28.0)$ & $27.2(26.0-28.3)$ \\
\hline $\mathrm{HbA1c}$ at inclusion visit (NGSP, \%) & $8.71(8.52-8.90)$ & $8.70(8.50-8.90)$ \\
\hline $\mathrm{HbA1c}$ at Inclusion visit (IFCC, $\mathrm{mmol} / \mathrm{mol})$ & $71.7(69.5-73.8)$ & $71.6(69.4-73.8)$ \\
\hline $\mathrm{HbA1c}$ at randomization visit (NGSP, \%) & $8.49(8.28-8.70)$ & $8.45(8.24-8.65)$ \\
\hline $\mathrm{HbA} 1 \mathrm{c}$ at Randomization (IFCC, $\mathrm{mmol} / \mathrm{mol}$ ) & $69.2(66.9-71.5)$ & $68.8(66.6-71.0)$ \\
\hline Years from diabetes onset to inclusion & $23.4(20.5-26.2)$ & $21.0(18.3-23.7)$ \\
\hline Total daily meal insulin dose (units) & $26.8(23.4-30.2)$ & $28.2(25.2-31.1)$ \\
\hline Total daily base insulin dose (units) & $29.6(26.8-32.5)$ & $30.9(27.3-34.5)$ \\
\hline Total daily insulin dose (units) & $56.4(51.2-61.6)$ & $59.1(53.3-64.9)$ \\
\hline \multirow[t]{2}{*}{ Number of insulin injections } & $4.90(1.06)$ & $4.75(0.86)$ \\
\hline & $\begin{array}{c}5.00(1.00-7.00) \\
n=69\end{array}$ & $\begin{array}{c}5.00(2.00-8.00) \\
n=73\end{array}$ \\
\hline Metformin used at randomization visit & $2(2.9 \%)$ & $0(0.0 \%)$ \\
\hline \multicolumn{3}{|l|}{ Smoking } \\
\hline Current & $7(10.1 \%)$ & $10(13.7 \%)$ \\
\hline Previous & $17(24.6 \%)$ & $15(20.5 \%)$ \\
\hline Never & $45(65.2 \%)$ & $48(65.8 \%)$ \\
\hline SD of glucose levels (mg/dL) (measured by CGM during 2 weeks) & $80.1(76.7-83.4)$ & $77.5(74.4-80.5)$ \\
\hline Proportion of time with low glucose levels (measured by CGM during & $2.31(2.39)$ & $2.06(2.42)$ \\
\hline 2 weeks) below $54 \mathrm{mg} / \mathrm{dL}[3.0 \mathrm{mmol} / \mathrm{L}]$ & 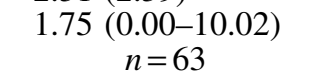 & $\begin{array}{c}1.11\left(\begin{array}{c}0.00-12.33) \\
n=69\end{array}\right.\end{array}$ \\
\hline \multirow{2}{*}{$\begin{array}{l}\text { Proportion of time with low glucose levels (measured by CGM during } \\
2 \text { weeks) below } 70 \mathrm{mg} / \mathrm{dL}[3.9 \mathrm{mmol} / \mathrm{L}]\end{array}$} & $5.52(4.33)$ & $5.12(4.24)$ \\
\hline & $\begin{array}{c}4.89\left(\begin{array}{c}0.00-16.12) \\
n=63\end{array}\right.\end{array}$ & $\begin{array}{c}4.32(0.09-19.97) \\
n=69\end{array}$ \\
\hline \multirow{2}{*}{$\begin{array}{l}\text { Average number of experienced hypoglycemia per week during the last } \\
2 \text { months (not based on blood glucose values, but subjective estimation) }\end{array}$} & $1.90(1.48)$ & $2.36(2.23)$ \\
\hline & $\begin{array}{c}1.75(0.00-7.00) \\
n=66\end{array}$ & $\begin{array}{c}2.00(0.00-12.00) \\
n=68\end{array}$ \\
\hline \multirow[t]{2}{*}{ Number of severe hypoglycemias past year } & $0.101(0.425)$ & $0.042(0.262)$ \\
\hline & $\begin{array}{c}0.000(0.000-3.000) \\
n=69\end{array}$ & $\begin{array}{c}0.000(0.000-2.000) \\
n=72\end{array}$ \\
\hline \multirow[t]{2}{*}{ Number of severe hypoglycemias past 5 years } & $0.884(3.042)$ & $0.319(0.709)$ \\
\hline & $\begin{array}{c}0.000(0.000-20.000) \\
n=69\end{array}$ & $\begin{array}{c}0.000(0.000-4.000) \\
n=72\end{array}$ \\
\hline \multirow[t]{2}{*}{ HCQ total scale at run-in visit } & $3.25(0.47)$ & $3.22(0.48)$ \\
\hline & $\begin{array}{c}3.22(2.13-4.00) \\
n=67\end{array}$ & $\begin{array}{c}3.28(2.11-4.00) \\
n=70\end{array}$ \\
\hline
\end{tabular}

For categorical variables $n(\%)$ is presented.

For continuous variables, Mean (95\% CI for mean) is presented.

For not normally distributed continuous variables, mean, SD, median, minimum and maximum are presented.

Severe hypoglycemic events are defined as unconsciousness due to hypoglycemia or need of assistance from another person to resolve the hypoglycemia.

CGM, continuous glucose monitoring; CI, confidence intervals; HbA1c, hemoglobin A1c; HCQ, Hypoglycemic Confidence Questionnaire; SD, standard deviation.

of time frames used (time 00:00-05:59 or 22:00-05:59), with $P<0.001$ in all cases (Table 2). Time with nocturnal glucose levels below $70 \mathrm{mg} / \mathrm{dL}(3.9 \mathrm{mmol} / \mathrm{L})$ (Time 00:00-05:59) was reduced by $48 \%$ (10.2 vs. 19.6 min each night $)$ and glucose levels $<54 \mathrm{mg} / \mathrm{dL}(<3.0 \mathrm{mmol} / \mathrm{L})$ by $65 \%$ (3.1 vs. $8.9 \mathrm{~min})$. Daytime hypoglycemia was significantly reduced by CGM compared with SMBG for both glucose levels evaluated, and both time frames, with $P<0.001$ in all cases (Table 2). Time with daytime glucose levels below $70 \mathrm{mg} / \mathrm{dL}(<3.9 \mathrm{mmol} / \mathrm{L}$ ) (Time 06:00 23:59) was reduced by $40 \%$ (29.5 vs. $48.8 \mathrm{~min})$ and for glucose levels $<54 \mathrm{mg} / \mathrm{dL}$ ( $<3.0 \mathrm{mmol} / \mathrm{L})$ by $54 \%$ ( $8.2 \mathrm{vs}$. $18.0 \mathrm{~min})$.

\section{Hypoglycemic episodes}

The number of episodes of hypoglycemia during CGM and conventional therapy are shown in Table 2. Episodes of both daytime and nocturnal hypoglycemia were fewer during CGM use for both the evaluated glucose levels and irrespective of time frames used, significant for all time frames for episodes below $54 \mathrm{mg} / \mathrm{dL}(3.0 \mathrm{mmol} / \mathrm{L})$.

During a 2-week period, there was overall an average of 9.46 episodes of daytime (time: 06:00-23:59) hypoglycemia [ $<70 \mathrm{mg} / \mathrm{dL}(<3.9 \mathrm{mmol} / \mathrm{L})]$ when using CGM and 11.78 while 

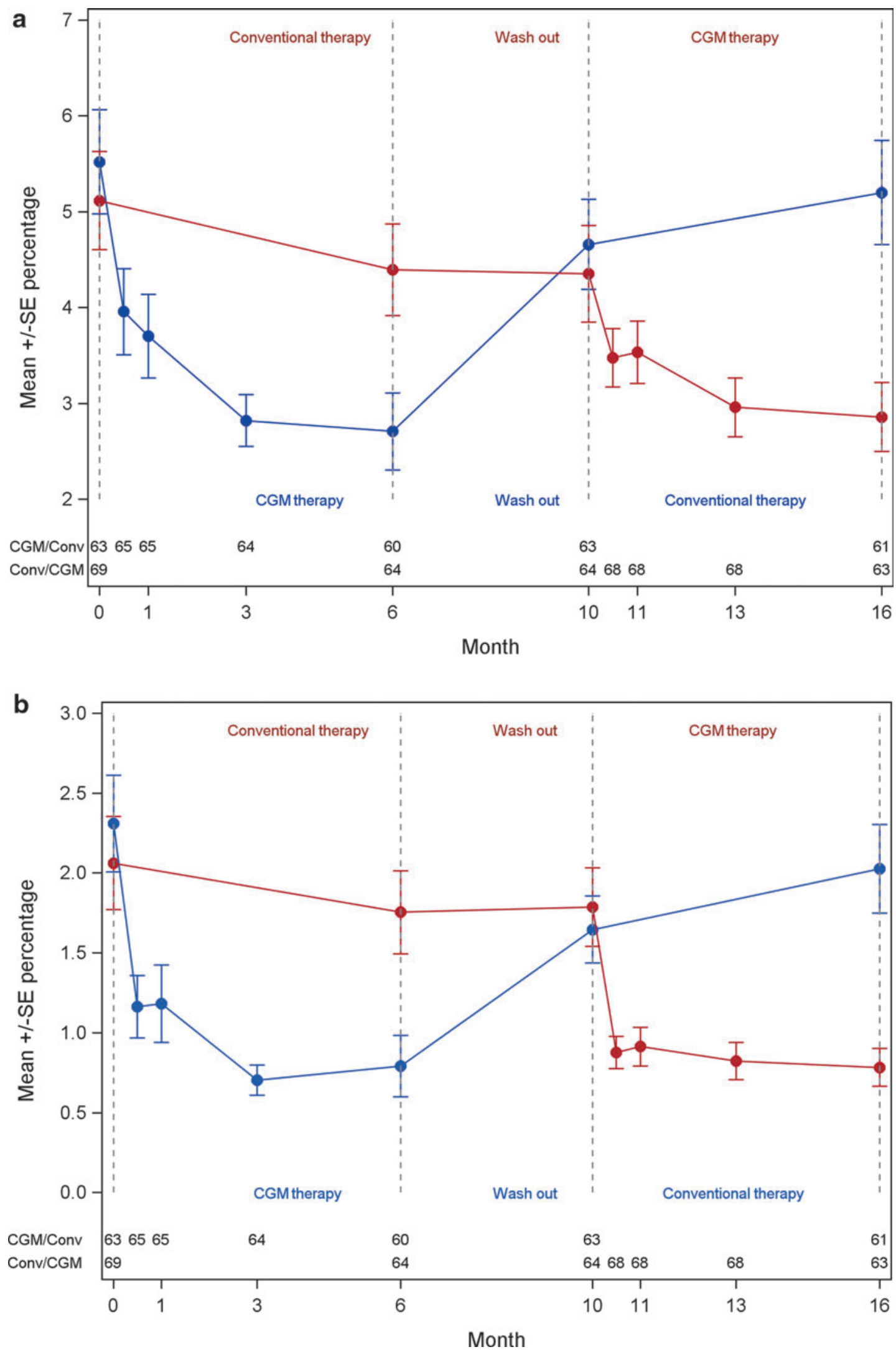

FIG. 1. Mean \pm SE percent time of glucose levels below (A) $70 \mathrm{mg} / \mathrm{dL}(3.9 \mathrm{mmol} / \mathrm{L})$ (B) $54 \mathrm{mg} / \mathrm{dL}(3.0 \mathrm{mmol} / \mathrm{L})$ and per treatment sequence over time (full analysis set population). CGM, continuous glucose monitoring. 
Table 2. Analysis of Daily and Nocturnal Percent of Time and Episodes with Low Glucose Levels (Full Analysis Set Population)

\begin{tabular}{|c|c|c|c|c|}
\hline & $\begin{array}{c}C G M \\
\text { (DexCom G4) }\end{array}$ & $\begin{array}{l}\text { Conventional } \\
\text { therapy }\end{array}$ & $\begin{array}{l}\text { Mean }(95 \% \text { CI) for difference } \\
\text { CGM-conventional treatment }\end{array}$ & $\mathrm{P}$ \\
\hline \multicolumn{5}{|c|}{ Percent of time with low glucose levels (measured by CGM during 2 weeks) below $70 \mathrm{mg} / \mathrm{dL}$ [3.9 mmol/L] } \\
\hline Daytime 06:00-23:59 & $\begin{array}{c}2.73(2.18-3.28) \\
n=123\end{array}$ & $\begin{array}{c}4.52(3.82-5.22) \\
n=125\end{array}$ & $\begin{array}{c}-1.77(-2.47 \text { to }-1.06) \\
n=123\end{array}$ & $<0.001$ \\
\hline Nighttime 00:00-05:59 & $\begin{array}{c}2.82(2.19-3.46) \\
n=123\end{array}$ & $\begin{array}{c}5.45(4.19-6.72) \\
n=125\end{array}$ & $\begin{array}{c}-2.63(-3.90 \text { to }-1.36) \\
n=123\end{array}$ & $<0.001$ \\
\hline Daytime 06:00-21:59 & $\begin{array}{c}2.81(2.25-3.36) \\
n=123\end{array}$ & $\begin{array}{c}4.77\left(\begin{array}{c}(4.02-5.53) \\
n=125\end{array}\right. \\
\end{array}$ & $\begin{array}{c}-1.93(-2.69 \text { to }-1.17) \\
n=123\end{array}$ & $<0.001$ \\
\hline Nighttime 22:00-05:59 & $\begin{array}{c}2.63(2.04-3.22) \\
n=123\end{array}$ & $\begin{array}{c}4.74(3.70-5.77) \\
n=125\end{array}$ & $\begin{array}{c}-2.11(-3.14 \text { to }-1.07) \\
n=123\end{array}$ & $<0.001$ \\
\hline \multicolumn{5}{|c|}{ Percent of time with low glucose levels (measured by CGM during 2 weeks) below $54 \mathrm{mg} / \mathrm{dL}$ [3.0 mmol/L] } \\
\hline Daytime 06:00-23:59 & $\begin{array}{c}0.76(0.54-0.98) \\
n=123\end{array}$ & 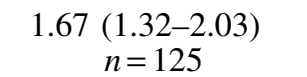 & $\begin{array}{c}-0.92(-1.25 \text { to }-0.59) \\
n=123\end{array}$ & $<0.001$ \\
\hline Nighttime 00:00-05:59 & $\begin{array}{c}0.85(0.54-1.16) \\
n=123\end{array}$ & $\begin{array}{c}2.46(1.74-3.18) \\
n=125\end{array}$ & $\begin{array}{c}-1.62(-2.37 \text { to }-0.87) \\
n=123\end{array}$ & $<0.001$ \\
\hline Daytime 06:00-21:59 & $\begin{array}{c}0.77(0.55-0.99) \\
n=123\end{array}$ & $\begin{array}{c}1.77(1.39-2.15) \\
n=125\end{array}$ & $\begin{array}{c}-1.00(-1.37 \text { to }-0.64) \\
n=123\end{array}$ & $<0.001$ \\
\hline Nighttime 22:00-05:59 & $\begin{array}{c}0.80(0.52-1.08) \\
n=123\end{array}$ & $\begin{array}{c}2.08(1.50-2.67) \\
n=125\end{array}$ & $\begin{array}{c}-1.29(-1.90 \text { to }-0.68) \\
n=123\end{array}$ & $<0.001$ \\
\hline \multicolumn{5}{|c|}{ Number of low glucose episodes (measured by CGM during 2 weeks) below $70 \mathrm{mg} / \mathrm{dL}$ [3.9 mmol/L] } \\
\hline Whole period & $\begin{array}{c}11.45(9.99-12.90) \\
n=123\end{array}$ & $\begin{array}{c}13.51(12.07-14.96) \\
n=125\end{array}$ & $\begin{array}{c}-2.06(-3.65 \text { to }-0.46) \\
n=123\end{array}$ & 0.01 \\
\hline Daytime 06:00-23:59 & $\begin{array}{c}9.46(8.21-10.70) \\
n=123\end{array}$ & $\begin{array}{c}11.78\left(\begin{array}{l}(10.45-13.12) \\
n=125\end{array}\right. \\
\text { n }\end{array}$ & $\begin{array}{c}-2.30(-3.73 \text { to }-0.87) \\
n=123\end{array}$ & 0.002 \\
\hline Nighttime 00:00-05:59 & $\begin{array}{c}2.57(2.09-3.05) \\
n=123\end{array}$ & $\begin{array}{c}2.92(2.42-3.42) \\
n=125\end{array}$ & $\begin{array}{c}-0.36(-0.94-0.22) \\
n=123\end{array}$ & 0.23 \\
\hline Daytime 06:00-21:59 & $\begin{array}{c}8.85(7.69-10.02) \\
n=123\end{array}$ & $\begin{array}{c}11.02(9.73-12.30) \\
n=125\end{array}$ & $\begin{array}{c}-2.13(-3.52 \text { to }-0.74) \\
n=123\end{array}$ & 0.003 \\
\hline Nighttime 22:00-05:59 & $\begin{array}{c}3.25(2.69-3.81) \\
n=123\end{array}$ & $\begin{array}{c}3.75(3.19-4.31) \\
n=125\end{array}$ & $\begin{array}{c}-0.50(-1.16-0.15) \\
n=123\end{array}$ & 0.13 \\
\hline \multicolumn{5}{|c|}{ Number of low glucose episodes (measured by CGM during 2 weeks) below $54 \mathrm{mg} / \mathrm{dL}$ [3.0 mmol/L] } \\
\hline Whole period & $\begin{array}{c}4.38(3.56-5.21) \\
n=123\end{array}$ & $\begin{array}{c}6.84(5.83-7.85) \\
n=125\end{array}$ & $\begin{array}{c}-2.46(-3.45 \text { to }-1.47) \\
n=123\end{array}$ & $<0.001$ \\
\hline Daytime 06:00-23:59 & $\begin{array}{c}3.50(2.81-4.20) \\
n=123\end{array}$ & $\begin{array}{c}5.58(4.73-6.42) \\
n=125\end{array}$ & $\begin{array}{c}-2.07(-2.94 \text { to }-1.19) \\
n=123\end{array}$ & $<0.001$ \\
\hline Nighttime 00:00-05:59 & $\begin{array}{c}1.03(0.77-1.30) \\
n=123\end{array}$ & $\begin{array}{c}1.76(1.32-2.20) \\
n=125\end{array}$ & $\begin{array}{c}-0.74(-1.20 \text { to }-0.28) \\
n=123\end{array}$ & 0.002 \\
\hline Daytime 06:00-21:59 & $\begin{array}{c}3.25(2.61-3.89) \\
n=123\end{array}$ & $\begin{array}{c}5.17\left(\begin{array}{c}(4.35-5.99) \\
n=125\end{array}\right.\end{array}$ & $\begin{array}{c}-1.90(-2.74 \text { to }-1.06) \\
n=123\end{array}$ & $<0.001$ \\
\hline Nighttime 22:00-05:59 & $\begin{array}{c}1.33(1.00-1.67) \\
n=123\end{array}$ & $\begin{array}{c}2.14(1.68-2.61) \\
n=125\end{array}$ & $\begin{array}{c}-0.83(-1.32 \text { to }-0.34) \\
n=123\end{array}$ & 0.001 \\
\hline
\end{tabular}

For continuous variables, mean, 95\% CI, and $n$ are presented. Fisher's nonparametric permutation test for crossover design was used.

using conventional therapy $(P=0.002)$. The corresponding episodes for glycemic value below $54 \mathrm{mg} / \mathrm{dL}(<3.0 \mathrm{mmol} / \mathrm{L})$ were 3.5 for CGM versus 5.58 for conventional therapy $(P<0.001)$.

\section{Glycemic variability}

The CV was lower during CGM compared with conventional therapy 0.37 versus 0.40 (difference $-0.03(-0.05$ to -0.02$), P<0.001)$, and when analyzed separately for the nocturnal period, time frame 00:00-05:59, (0.35 vs. 0.38, $P<0.001)$ and daytime periods, time 06:00-23:59, (0.37 vs. $0.41, P<0.001)$. Corresponding findings existed when other time frames were used (Table 3). The SD and the MAGE were also lower both during nocturnal and daytime periods with $P<0.001$ in all cases (Table 3 ).

\section{Sensitivity analyses of time on hypoglycemia} and number of episodes of hypoglycemia

Sensitivity analyses using MI of percent time on hypoglycemia showed robust results compared with analyses performed on the FAS population, and all analyses were significant with $P<0.001$ (Supplementary Table S1; Supplementary Data are available at http://online.liebertpub. com/doi/suppl/10.1089/dia.2017.0363). The RR of percent time with glucose levels $<70 \mathrm{mg} / \mathrm{dL}(<3.9 \mathrm{mmol} / \mathrm{L})$ was 0.58 (0.49-0.70) for the FAS population, compared with $0.61(0$. 51-0.73) for the first MI analysis (using demographics and baseline characteristics for imputation) and $0.62(0.51-0.74)$ for the second MI analysis (also including baseline HbA1c and percent time on low hypoglycemia for imputation). For percent time with glucose levels $<54 \mathrm{mg} / \mathrm{dL}(<3.0 \mathrm{mmol} / \mathrm{L})$ the 
Table 3. Analysis of Daily And Nocturnal Glycemic Variability Estimated By Standard Deviation, Coefficient of Variation, And Mean Amplitude of Glycemic Excursions from Glucose Levels (Full Analysis Set Population)

\begin{tabular}{|c|c|c|c|c|}
\hline & $\begin{array}{c}C G M \\
(\text { Dexcom G4) }\end{array}$ & $\begin{array}{l}\text { Conventional } \\
\text { therapy }\end{array}$ & $\begin{array}{c}\text { Least square mean } \\
(95 \% \text { CI })^{\mathrm{a}} \text { for difference } \\
\text { CGM-conventional treatment }\end{array}$ & $\mathrm{P}$ \\
\hline \multicolumn{5}{|c|}{ SD of glucose levels (mg/dL) (measured by CGM during 2 weeks) } \\
\hline Daytime 06:00-23:59 & $\begin{array}{c}69.31(67.09-71.53) \\
n=123\end{array}$ & $\begin{array}{c}77.49\left(\begin{array}{c}(75.14-79.84) \\
n=125\end{array}\right.\end{array}$ & $-8.42(-10.69$ to -6.15$)$ & $<0.001$ \\
\hline Nighttime 00:00-05:59 & $\begin{array}{c}64.33(61.52-67.13) \\
n=123\end{array}$ & $\begin{array}{c}71.32(68.20-74.43) \\
n=125\end{array}$ & $-7.16(-10.59$ to -3.74$)$ & $<0.001$ \\
\hline Daytime 06:00-21:59 & $\begin{array}{c}68.86(66.63-71.10) \\
n=123\end{array}$ & $\begin{array}{c}76.71(74.28-79.14) \\
n=125\end{array}$ & $-8.07(-10.50$ to -5.63$)$ & $<0.001$ \\
\hline Nighttime 22:00-05:59 & $\begin{array}{c}66.17(63.51-68.83) \\
n=123\end{array}$ & $\begin{array}{c}74.33(71.50-77.17) \\
n=125\end{array}$ & $-8.37(-11.40$ to -5.34$)$ & $<0.001$ \\
\hline \multicolumn{5}{|c|}{ CV of glucose levels (mg/dL) (measured by CGM during 2 weeks) } \\
\hline Daytime 06:00-23:59 & $\begin{array}{c}0.37(0.36-0.38) \\
n=123\end{array}$ & $\begin{array}{c}0.41(0.39-0.42) \\
n=125\end{array}$ & $-0.04(-0.05$ to -0.03$)$ & $<0.001$ \\
\hline Nighttime 00:00-05:59 & $\begin{array}{c}0.35(0.33-0.36) \\
n=123\end{array}$ & $\begin{array}{c}0.38(0.36-0.40) \\
n=125\end{array}$ & $-0.03(-0.05$ to -0.02$)$ & $<0.001$ \\
\hline Daytime 06:00-21:59 & $\begin{array}{c}0.37(0.36-0.38) \\
n=123\end{array}$ & $\begin{array}{c}0.41(0.40-0.42) \\
n=125\end{array}$ & $-0.04(-0.05$ to -0.03$)$ & $<0.001$ \\
\hline Nighttime 22:00-05:59 & $\begin{array}{c}0.35(0.34-0.36) \\
n=123\end{array}$ & $\begin{array}{c}0.38(0.37-0.40) \\
n=125\end{array}$ & $-0.04(-0.05$ to -0.02$)$ & $<0.001$ \\
\hline \multicolumn{5}{|c|}{ MAGE of glucose levels (mg/dL) (measured by CGM during 2 weeks) } \\
\hline Daytime 06:00-23:59 & $\begin{array}{c}159.10(154.11-164.10) \\
n=123\end{array}$ & $\begin{array}{c}180.23(174.64-185.81) \\
n=127\end{array}$ & $-21.39(-27.08$ to -15.71$)$ & $<0.001$ \\
\hline Nighttime 00:00-05:59 & $\begin{array}{c}148.61(141.68-155.54) \\
n=119\end{array}$ & $\begin{array}{c}163.68(156.14-171.21) \\
n=124\end{array}$ & $-15.59(-24.57$ to -6.60$)$ & $<0.001$ \\
\hline Daytime 06:00-21:59 & $\begin{array}{c}159.29(154.31-164.28) \\
n=123\end{array}$ & $\begin{array}{c}178.33(172.62-184.04) \\
n=127\end{array}$ & $-18.88(-24.76$ to -13.01$)$ & $<0.001$ \\
\hline Nighttime 22:00-05:59 & $\begin{array}{c}154.00(147.58-160.41) \\
n=121\end{array}$ & $\begin{array}{c}169.05(162.41-175.68) \\
n=126\end{array}$ & $-15.70(-23.28$ to -8.12$)$ & $<0.001$ \\
\hline
\end{tabular}

For continuous variables mean, 95\% CI and $n$ are presented; For categorical variables $n$ and percent are presented.

${ }^{a}$ LSM $(95 \% \mathrm{CI})$ and $P$-value are obtained from SAS procedure PROC GLM with sequence, patient(sequence), period, and treatment as class variables.

$\mathrm{CV}$, coefficient of variation; MAGE, mean amplitude of glycemic excursions.

corresponding RRs were $0.42(0.32-0.54)$ for the FAS population and $0.45(0.35-0.59)$ for both MI analyses. Similarly, robust results were obtained for the number of hypoglycemic episodes (Supplementary Table S1). Effects over time by CGM sensitivity analyses were performed for a subgroup of participants having CGM data at all time points (Supplementary Fig. S2), which showed similar results as in the primary analysis (Fig. 1).

\section{Hypoglycemia confidence}

Overall hypoglycemia confidence was greater at the end of the CGM period than at the end of the SMBG period, 3.40 (95\% CI 3.32-3.47) versus 3.27 (95\% CI 3.18-3.35) with $P<0.001$. Examination of individual items (Table 4) revealed that CGM use was associated with greater confidence than SMBG use in being able to: avoid serious problems due to hypoglycemia $(P=0.0020)$, detect and respond to falling glucose levels and thus preventing hypoglycemia $(P=0.0033)$, and continue with one's chosen lifestyle activities despite the risk of hypoglycemia $(P=0.022)$. In addition, CGM use was linked to greater confidence in social situations $(P=0.016)$.

\section{Severe hypoglycemia}

During CGM therapy there was one event of severe hypoglycemia in contrast to five events during conventional therapy. There were a further seven events of severe hypoglycemia during the washout period when all patients were on conventional therapy. There were no obvious numerical differences for any other adverse events between the treatments. ${ }^{7}$

\section{Discussion}

The current evaluations from a randomized crossover trial shows that intensive insulin treatment with MDI and CGM, compared with MDI and SMBG, among adults with type 1 diabetes led to reduced time and episodes of nocturnal and daytime hypoglycemia, whereas HbA1c was also reduced. Continuous use of CGM was needed to obtain these effects. Moreover, our current analyses of the Hypoglycemia Confidence Scale indicate that when using CGM, participants experience greater confidence regarding hypoglycemia in social situations and less limitations in their daily life. Participants felt more confident in detecting and responding to low glucose values, thereby avoiding hypoglycemia. 
Table 4. Analysis Of Hypoglycemia Confidence Questionnaire Items During Continuous Glucose Monitoring And Conventional Treatment (Full Analysis Set Population)

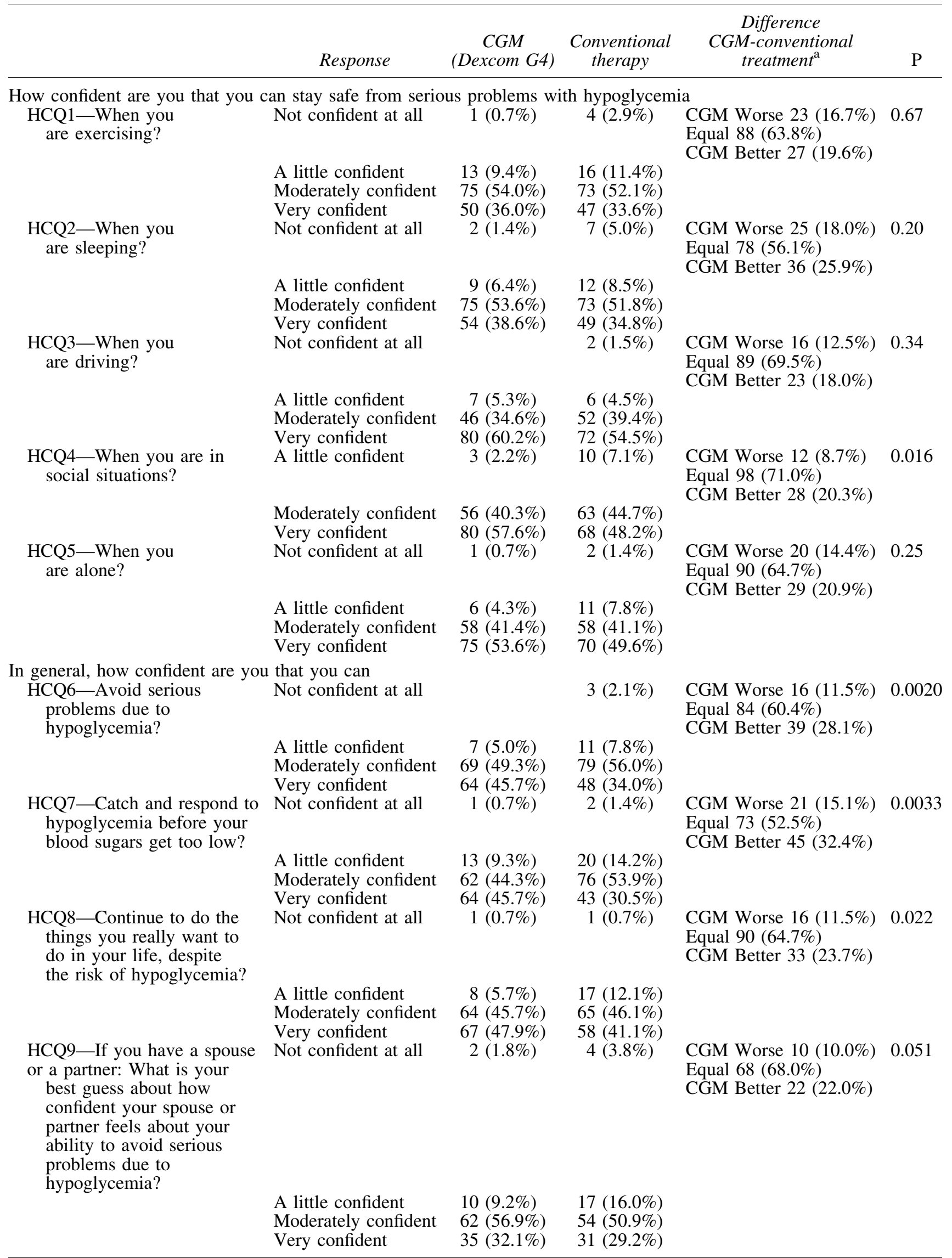

For categorical variables $n$ and percent are presented.

${ }^{a}$ Fisher's nonparametric permutation test between the treatment sequences on the difference between periods was performed. 
The DIAMOND study evaluated nocturnal and daytime hypoglycemia for persons on MDI using CGM versus SMBG and found that time in hypoglycemia $(<70 \mathrm{mg} / \mathrm{dL} / 3.9 \mathrm{mmol} / \mathrm{L})$ was significantly lower for those with CGM both during day and night time. ${ }^{11}$ Previous randomized multicenter CGM trials have been performed either with persons on CSII therapy or persons with either CSII or MDI. ${ }^{12,14-19}$ In the STAR-3 study, initiating CGM simultaneously as insulin pump treatment compared with persons continuing on MDI showed no effect on hypoglycemia, although $\mathrm{HbA} 1 \mathrm{c}$ was lowered,. ${ }^{14}$ In the JDRF CGM study, including both persons with insulin pumps and treated with MDI, no effect was found on hypoglycemia although glucose readings were available only for a few days. ${ }^{15}$ In its follow-up study, investigators found there was a greater reduction in time with glucose values $\leq 70 \mathrm{mg} / \mathrm{dL}$ ( $<3.9 \mathrm{mmol} / \mathrm{L}$ ) over a 6 -month period for those with CGM. ${ }^{16}$ In the SWITCH study, participants were randomized in a crossover design to CGM or SMBG during insulin pump treatment and showed that hypoglycemia was reduced with CGM for glucose levels $<70 \mathrm{mg} / \mathrm{dL}$ along with $\mathrm{HbA} 1 \mathrm{c}$-lowering effect. ${ }^{17}$ In the IN CONTROL study, which included persons with hypoglycemic unawareness, CGM significantly increased time in euglycemia and reduced severe hypoglycemia. ${ }^{12}$ Another randomized study, including both persons with CSII and MDI, showed that time spent with glucose values $<63 \mathrm{mg} / \mathrm{dL}$ was significantly reduced during CGM. ${ }^{18}$ It should be noted the hypoglycemia confidence questionnaire is relatively new and has generally not been evaluated in other multicenter randomized trials. ${ }^{9,12,14-19}$

In the current study, extensive evaluations on the effect of hypoglycemia were performed using two glucose level cutoffs, $70 \mathrm{mg} / \mathrm{dL}(<3.9 \mathrm{mmol} / \mathrm{L})$ and $54 \mathrm{mg} / \mathrm{dL}(<3.0 \mathrm{mmol} / \mathrm{L})$, and two-time frames for nocturnal and daytime hypoglycemia, with both evaluating time and episodes of hypoglycemia. All analyses showed consistent results of CGM substantially reducing both time and episodes of hypoglycemia. We recently showed that to obtain an effect of CGM on HbA1c in persons with type 1 diabetes and treated with MDI, continuous use is needed, ${ }^{7}$ which has also been shown for insulin pump users. ${ }^{12,14}$ In the present study, we found that continuous use of monitoring is needed to obtain beneficial effects on reducing hypoglycemia. When CGM use was stopped during the washout period, time in hypoglycemia reverted to levels similar with conventional therapy (Fig. 1). Therefore, a key issue for CGM therapy to be able to improve both $\mathrm{HbA} 1 \mathrm{c}$ and time in hypoglycemia long term is continuous use of the system.

A likely explanation for the reduced time in both nocturnal and daytime hypoglycemia with CGM is that participants receive continuous information about glucose values, including whether these values are rising or decreasing. ${ }^{20}$ With this information, it is possible to take early preventive actions in many situations, for example, easily checking glucose levels and trends before physical activity or bed time and deciding whether carbohydrates are needed if the glucose trend is decreasing or taking an extra insulin dose if increasing. The alarms are also likely to be an important function in signaling before glucose values get too low or high. In contrast using SMBG for information about glucose levels, only a very small proportion of the continuous glucose curve is retrieved and does not provide information about trends. ${ }^{4-6}$ Current analyses of $\mathrm{CV}$, as a measure of glycemic variability, was significantly less during both day and nighttime with CGM therapy, which further supports the glucose-stabilizing effect of CGM. Of note, the CGM system used in the study (Dexcom G4), has shown high accuracy and treatment experience in short-term comparative trials, which may be essential for the current results. ${ }^{21-23}$ This study has shown that CGM improves both time in hypoglycemia and glycemic variability, but it is important to note that other factors can also lead to improvements. ${ }^{24,25}$

The current study implies that for adults treated with MDI, a more efficient way to improve HbA1c is now available, which at the same time reduces both nocturnal and daytime hypoglycemia. The fact that CGM patients felt more confident that hypoglycemia was not limiting their daily lives or negatively impacting social situations and that they were generally more confident regarding their ability to avoid hypoglycemia is of critical importance. Since this is the first study to examine the specific features of hypoglycemic confidence resulting from CGM use in a randomized setting, it is of value to consider these findings and their potential implications in greater detail. It seems likely that the key result was that CGM patients gained a greater sense of selfefficacy that they could avoid and/or detect and respond to mild hypoglycemia before it grew more serious. Consequently, they felt more secure in their ability to participate in daily activities (including social activities) without worrying about hypoglycemia. This would seem to be an essential benefit of CGM, to make life easier for patients, and allows them to feel more confident about participating in their own lives with fewer restrictions and worries. It is likely that this is a key contributor to broader quality of life benefits and may largely explain the significantly greater overall well-being and treatment satisfaction earlier that was described in the original study report. ${ }^{7}$

Given these findings, however, it is difficult to explain why CGM patients did not feel more confident while driving, sleeping, or exercising. It is possible that factors that we could not control for may have influenced these findings, such as how frequently patients were driving and/or whether patients were living alone or with a partner (which may have influenced confidence regarding hypoglycemia while sleeping). It is also possible that most patients already felt generally confident in these specific situations at baseline (therefore leaving little room for additional improvement). We plan to examine this latter possibility in future analyses of this dataset.

In total, we would suggest that, together with the earlier reported findings of improved well-being and treatment satisfaction, the current results further support the use of CGM for adults with type 1 diabetes.

A limitation of the study is that treatment could not be blinded, thus participants were aware of the intervention. This may have influenced the treatment effects to some extent. Although the current reduction in nocturnal and daytime hypoglycemia is clinically important, other treatment alternatives are needed for persons with type 1 diabetes to fully avoid hypoglycemia on a broad level. In addition, the current results are restricted to adults with $\mathrm{HbA} 1 \mathrm{c}>7.5 \%$ (58 $\mathrm{mmol} / \mathrm{mol})$.

In conclusion, CGM reduces both nocturnal and daytime hypoglycemia as well as the number of hypoglycemic episodes while lowering HbA1c in adults with type 1 diabetes 
treated with MDI. In addition, both daytime and nighttime glycemic variability is reduced by CGM in persons with T1D treated with MDI. As a result, persons reported greater confidence detecting and managing hypoglycemia, especially in social situations, and indicated greater conviction that they could live more freely and safely despite the risk of hypoglycemia.

\section{Acknowledgments}

The trial was sponsored by the NU Hospital Group, Trollhättan and Uddevalla, Sweden. The steering committee of this study consists of M.L. (PI), W.P., I.B.H., T.H., J.B., and S.D. The authors want to thank all participating sites for covering costs of the study, including salaries for participating personnel. They want to thank Aldina Pivodic (MSc), at the Statistiska Konsultgruppen for assistance in statistical calculations and Joseph Murphy, J.D., for language editing. The trial was investigator initiated and the manufacturer of the CGM system was not involved in the design and conduct of the study; collection, management, analysis, and interpretation of the data; preparation, review, or approval of the article; or decision to submit the article for publication. The NU Hospital Group received financial support for the current trial and CGM systems and sensors from Dexcom, Inc. Furthermore, financial support was received from the Swedish government (under the Avtal om Läkareutbildning och Medicinsk Forskning [Agreement for Medical Education and Research]).

\section{Author Disclosure Statement}

W.P. has consulted for Dexcom and Abbott Diabetes Care. J.B. has served on advisory boards for Abbott Diabetes Care, Insulet Corporation, Integrity Applications, Novo Nordisk, and Sanofi-Aventis; has done lectures for Abbott Diabetes Care, Astra Zeneca, Novo Nordisk, and Sanofi-Aventis. I.B.H. has consulted for Abbott Diabetes Care, Roche, and Intarcia. T.N. has received unrestricted grants from Astra Zeneca and Novo Nordisk, and he has served on national advisory boards of Novo Nordisk, Sanofi-Aventis, Eli Lilly, and Boehringer Ingelheim. M.W. has served on advisory boards and/or lectured for MSD, Lilly, Novo Nordisk and Sanofi, and has organized a professional regional meeting sponsored by Lilly, Rubin Medical, Sanofi, Novartis and Novo Nordisk. T.H. has received grants from Adocia, Becton Dickinson, Astra Zeneca, Biocon, Boehringer Ingelheim, Dance Pharmaceuticals, Eli Lilly, Grünenthal, Gulf Pharmaceuticals, Johnson \& Johnson, Marvel, Medimmune, Medtronic, Mylan, Novartis, Novo Nordisk, Roche Diagnostics, Sanofi, Senseonics, and Zealand Pharma. He also reports personal fees from Eli Lilly, Mylan, and Novo Nordisk. E.S. has done lectures for Novo Nordisk, Sanofi, and Eli Lilly. J.H. has served on advisory boards for Sanofi-Aventis, Lilly, Merck Sharp \& Dohme, Jensen Cilag, Novo Nordisk, Astra Zeneca, Dexcom, and Abbott; has done lectures for Sanofi-Aventis, Boehringer-Ingelheim, Lilly, Merck Sharp \& Dohme, Novo Nordisk, and Astra Zeneca. M.L. has received grants from Astra Zeneca, Dexcom, Novo Nordisk, been a consultant or received honoraria from Dexcom, Eli Lilly, Medtronic, Novo Nordisk, and Rubin Medical and participated in advisory boards for MSD and Novo Nordisk. A.F.O., S.D., and H.W. have nothing to disclose.

\section{References}

1. DCCT Study Group: The Effect of intensive treatment of diabetes on the development and progression of long-term complications in insulin-dependent diabetes mellitus. $\mathrm{N}$ Engl J Med 1993;329:977-986.

2. Nathan DM, Cleary PA, Backlund JY, et al.: Intensive diabetes treatment and cardiovascular disease in patients with type 1 diabetes. N Engl J Med 2005;353:26432653.

3. Misso ML, Egberts KJ, Page M, et al.: Continuous subcutaneous insulin infusion (CSII) versus multiple insulin injections for type 1 diabetes mellitus. Cochrane Database Syst Rev 2010;1:CD005103.

4. Hansen MV, Pedersen-Bjergaard U, Heller SR, et al.: Frequency and motives of blood glucose self-monitoring in type 1 diabetes. Diabetes Res Clin Pract 2009;85: 183-188.

5. Miller KM, Beck RW, Bergenstal RM, et al.: Evidence of a strong association between frequency of self-monitoring of blood glucose and hemoglobin A1c levels in T1D exchange clinic registry participants. Diabetes Care 2013;36:20092014.

6. Evans JM, Newton RW, Ruta DA, et al.: Frequency of blood glucose monitoring in relation to glycaemic control: observational study with diabetes database. BMJ 1999;319: 83-86.

7. Lind M, Polonsky W, Hirsch IB, et al.: Continuous glucose monitoring vs conventional therapy for glycemic control in adults with type 1 diabetes treated with multiple daily insulin injections: the GOLD randomized clinical trial. JAMA 2017;317:379-387.

8. Lind M, Polonsky W, Hirsch IB, et al.: Design and methods of a randomized trial of continuous glucose monitoring in persons with type 1 diabetes with impaired glycemic control treated with multiple daily insulin injections (GOLD Study). J Diabetes Sci Technol 2016;10: 754-761.

9. Polonsky, WH, Fisher, L, Hessler D, Edelman SV: Investigating hypoglycemic confidence in type 1 and type 2 diabetes. Diabetes Technol Ther 2017;19:131-136.

10. Hirsch IB: Insulin analogues. N Engl J Med 2005;352: 174-183.

11. Beck R, Riddlesworth T, Ruedy K, et al.: Effect of continuous glucose monitoring on glycemic control in adults with type 1 diabetes using insulin injections: the DIAMOND randomized clinical trial. JAMA 2017;317:371378.

12. Van Beers C, DeVries J, Kleijer S, et al.: Continuous glucose monitoring for patients with type 1 diabetes and impaired awareness of hypoglycaemia (IN CONTROL): a randomised, open-label, crossover trial. Lancet Diabetes Endocrinol 2016;4:893-902.

13. Baghurst PA: Calculating the mean amplitude of glycemic excursion from continuous glucose monitoring data. Diabetes Tchnol Ther 2011;13:296-302.

14. Bergenstal RM, Tamborlane V, Ahmann A, et al.: Effectiveness of sensor-augmented insulin-pump therapy in type 1 diabetes. N Engl J Med 2010;363:311-320.

15. Juvenile Diabetes Research Foundation Continuous Glucose Monitoring Study Group: Continuous glucose monitoring and intensive treatment of type 1 diabetes. $\mathrm{N}$ Engl J Med 2008;359:1464-1476.

16. JDRF-Study Group: Effectiveness of continuous glucose monitoring in a clinical care environment: evidence from 
the Juvenile Diabetes Research Foundation Continuous Glucose Monitoring (JDRF-CGM) trial. Diabetes Care 2010;33:17-22.

17. Battelino T, Conget I, Olsen B, et al.; SWITCH Study Group. The use and efficacy of continuous glucose monitoring in type 1 diabetes treated with insulin pump therapy: a randomised controlled trial. Diabetologia 2012;55: 3155-3162.

18. Battelino T, Phillip M, Bratina N, et al.: Effect of continuous glucose monitoring on hypoglycemia in type 1 diabetes. Diabetes Care 2011;34:795-800.

19. Pickup JC, Freeman SC, Sutton AJ: Glycaemic control in type 1 diabetes during real time continuous glucose monitoring compared with self monitoring of blood glucose: meta-analysis of randomised controlled trials using individual patient data. BMJ 2011;343:d3805.

20. Hirsch I: Clinical review: realistic expectations and practical use of continuous glucose monitoring for the endocrinologist. J Clin Endocrinol Metab 2009;94:22322238.

21. Matuleviciene V, Joseph JI, Andelin M, et al.: A clinical trial of the accuracy and treatment experience of the Dexcom G4 Sensor (Dexcom G4 System) and Enlite Sensor (Guardian REAL-Time System) tested simultaneously in ambulatory patients with type 1 diabetes. Diabetes Technol Ther 2014;16:759-767.

22. Kropff J, Bruttomesso D, Doll W, et al.: Accuracy of two continuous glucose monitoring systems: a head-to-head comparison under clinical research center and daily life conditions. Diabetes Obes Metab 2015;17:343-349.

23. Damiano ER, McKeon K, El-Khatib FH, et al.: A comparative effectiveness analysis of three continuous glucose monitors: the navigator, G4 Platinum and Enlite. J Diabetes Sci Technol 2014;8:699-708.

24. Little SA, Leelarathna, L, Walkinshaw E, et al.: Recovery of hypoglycemia awareness in long-standing type 1 diabetes: a multicenter $2 \times 2$ factorial randomized controlled trial comparing insulin pump with multiple daily injection and continuous with conventional glucose self-monitoring (HypoCOMPaSS). Diabetes Care 2014:37:2114-2122.

25. Tan HK, Little SA, Leelarathna L, et al.: Low-blood glucose avoidance training improves glycemic variability in adults with type 1 diabetes complicated by impaired awareness of hypoglycemia: HypoCOMPaSS trial. Diabetes Care 2016;39:e56-e58.

Address correspondence to:

Marcus Lind, MD, PhD

Diabetes Outpatient Clinic

Uddevalla Hospital

Uddevalla 45180

Sweden

E-mail: lind.marcus@telia.com 